\title{
A constructivist approach toward a general definition of biodiversity
}

\author{
Meinard, Yves ; Coq, Sylvain ; Schmid, Bernhard
}

\begin{abstract}
Biodiversity sciences witness a double dynamic. Whereas the need for interdisciplinary approaches is increasingly appreciated, most disciplinary studies are still confined to developing operational, discipline-specific indices. We show that a reassessment of the general notion of biodiversity is needed to clarify this situation. We advocate a new approach, according to which the main usefulness of this notion is not to capture quantitatively biological objects or processes, but to organize meaningful and coherent interdisciplinary interactions by constructively criticizing disciplinary studies. We apply this approach to ecological-economic models, in the hope of launching more fruitful critical dialogs between economists and biologists.
\end{abstract}

DOI: https://doi.org/10.1080/21550085.2014.885490

Posted at the Zurich Open Repository and Archive, University of Zurich

ZORA URL: https://doi.org/10.5167/uzh-95800

Journal Article

Originally published at:

Meinard, Yves; Coq, Sylvain; Schmid, Bernhard (2014). A constructivist approach toward a general definition of biodiversity. Ethics, Policy Environment, 17(1):88-104.

DOI: https://doi.org/10.1080/21550085.2014.885490 


\section{A constructivist approach towards a general definition of biodiversity}

Yves MEINARD*, Sylvain COQ ${ }^{\#}$, Bernhard Schmid*

*Institut für Evolutionsbiologie und Umweltwissenschaften, Universität Zürich, Zürich, SWITZERLAND

${ }^{\#}$ Centre d'Ecologie Fonctionnelle et Evolutive, Montpellier, FRANCE

Abstract-Biodiversity sciences witness a double dynamic. Whereas the need for interdisciplinary approaches is increasingly appreciated, most disciplinary studies are still confined to developing operational, discipline-specific indices. We show that a reassessment of the general notion of biodiversity is needed to clarify this situation. We advocate a new approach, according to which the main usefulness of this notion is not to capture quantitatively biological objects or processes, but to organize meaningful and coherent interdisciplinary interactions by constructively criticizing disciplinary studies. We apply this approach to ecological-economic models, in the hope of launching more fruitful critical dialogs between economists and biologists.

Keywords: surrogates, politics and policy, philosophy, economics, ecosystem management

\section{Introduction}

"Biodiversity" is a new term introduced in the 1980s (Wilson \& Peters 1988). Its use has increased tremendously (Loreau 2010) since the Convention on Biological Diversity (CBD) in 1992, in which "biodiversity", as shorthand to "biological diversity", is defined as referring to 
"the variability among living organisms from all sources including, inter alia, terrestrial, marine and other aquatic ecosystems and the ecological complexes of which they are part; this includes diversity within species, between species and ecosystems" (UN Conference on Environment and Development, Rio de Janeiro, 1992, Convention on Biological Diversity, Article 2). Several reformulations of this definition have been introduced in the literature, two prominent example being Groves et al. (2002)'s definition of "biodiversity" as "the variety of living organisms; the biological complexes in which they occur, and the ways in which they interact with each other and the physical environment", and Purvis \& Hector (2000)'s definition of "biodiversity" as "the sum total of all biotic variation from the level of genes to ecosystems". All these definitions are markedly similar, especially in that they are anchored in the notions of diversity, variety and variability, in effect taken as synonyms. Therefore, in the remainder of this article, we will talk about "the CBD definition and its reformulations" to collectively refer to all these definitions. Most biologists content themselves with such definitions (Mace et al. 2012), used as a basis of a shared tacit understanding (Schläpfer et al. 1999). They usually skip from abstract discussions on the general definition of biodiversity directly to technical discussions on discipline-specific indices of biodiversity. Some ecological studies thus approximate biodiversity by species richness (Fleishman et al. 2006), sometimes weighted by relative abundance (Colyvan et al. 2009). Other studies, purporting to shed light on other aspects of biodiversity, favor more complex indices, mainly based on functional traits (Mason et al. 2003, Petchey \& Gaston 2002), phylogenetic distances (Faith 1992) or habitat structure (Noss 1990). As these various approaches improve their respective methodologies, the various indices become more sophisticated and better-adapted to capture specific aspects of biodiversity. In that sense, the biological literature witnesses a specialization of approaches to biodiversity (Petchey et al. 2009, Schleuter et al. 2010). At the same time, however, many authors emphasize that protection, monitoring and valuation of 
51 biodiversity raise multifaceted societal, economic, political and scientific issues, thereby 52 requiring a new integrative, interdisciplinary approach (Tassy 2006, Maris 2010, Loreau 2010, Meinard 2011, Meinard \& Grill 2011).

54 Our aim in this article is not to add our piece to an already long list of reviews and historical presentations of these trends, but rather to investigate whether a general definition of biodiversity can reconcile these two trends. Indeed, although they point in divergent directions, specialization and integration need not contradict each other: a general definition of biodiversity should allow the integrative, interdisciplinary approach to encompass and combine the various results of the specialized studies, each focused on its own operational index of biodiversity. Such a general definition would be a clearly articulated overarching concept of biodiversity, broad enough to encompass all the various specialized approaches, but at the same time explanatory enough not to trivialize the integrative, interdisciplinary approach. Do the CDB definition and its reformulations fulfill this requirement? Here we advance a negative answer to this question, and we suggest a new, alternative approach towards the general definition of biodiversity.

Indeed, although the CBD definition and its reformulations certainly seem unequivocal at first sight, it turns out that they can be understood in markedly different fashions, depending on the method used to clarify and elaborate them. These definitions therefore do not guarantee that, when using the term "biodiversity" in collaborations with colleagues from other disciplines, we can take it for granted that we understand each other. This defect undoubtedly makes these

71 definitions unsuitable for the purpose of integrating different disciplines by interdisciplinary 72 interactions. The classical approaches to clarify and elaborate the CBD general definition and 73 its reformulations, which will be explored in more detail in this article, can be grouped into 74 three types: 
- The first approach holds that the CBD definition and its reformulations are clear and unequivocal because the notion of diversity, in which they are anchored, is itself clear and unequivocal. We call this the "ordinary approach" because it is based on the meaning of the term "diversity" in the ordinary, everyday language. The other two approaches admit that the latter meaning is more difficult to ascertain than it might seem at first sight, and that this first approach is therefore trivializing.

- The second approach holds that "biodiversity" can be implicitly defined, but that any such definition is doomed to critically depend on arbitrary choices. This approach thus suggests that trying to find a general definition of biodiversity is a futile, useless exercise, because countless different, but equally acceptable, definitions can be carved out. We call it the "conventionalist approach" because, in the philosophical jargon, such arbitrary choices are called "conventions" (Lewis 2002).

- The third approach, which can be called "the unit-and-differences" approach, has been prominently developed by Maclaurin \& Sterelny (2008). This approach develops a much more ambitious vision, according to which our understanding of the notion of biodiversity should be based on an account of a project that plays a crucial role in the scientific endeavor: the one of identifying causally relevant units, differences and dissimilarities.

These three approaches are markedly different and, as their more precise presentation will illustrate, they can have markedly different implications. It is therefore necessary, in order to assess whether the CBD definition and its reformulations can reconcile the two trends portrayed above, to start by assessing the credentials of these three approaches. We will argue that the first two approaches are unsatisfactory, and that the third one, although more 
100 powerful, misses a crucial dimension of the importance of the notion of biodiversity in the 101 current scientific debates. In order to make up for this lacuna, we advocate a forth, 102 "constructivist approach" (Habermas 1983, Gadamer 2004), according to which the meaning 103 of the term "biodiversity" emerges from a task progressively articulated by developing

104 interdisciplinary studies. In this theory, biodiversity is not a pre-existing entity, but a dynamic 105 concept built by the very fact that several disciplines coherently work together.

106 We should emphasize at the outset that this approach does not purport to provide for a new 107 measurable concept. In this approach, the general notion of biodiversity is not useful for 108 specific scientific experiments, calculations or measures (discipline-specific biodiversity 109 indices are the relevant tools for these purposes). However, the general definition of 110 biodiversity, suitably determined, is a useful concept to organize interactions between

111 disciplines and to ensure that the results of each biodiversity discipline can make sense for the 112 other biodiversity disciplines. This role, unfortunately neglected by the other approaches 113 toward the definition of biodiversity, can be of major importance in the current context of the 114 implementation of the agenda of the Intergovernmental Science-Policy Platform on 115 Biodiversity and Ecosystem Services (IPBES). We illustrate how the general notion of 116 biodiversity can play this role with an example: we show that the constructivist approach can 117 shed light on the true meaning of the results of ecological-economic modeling.

\section{The three classical approaches towards a general definition of biodiversity}

120 Although the literature on discipline- and problem-dependent indices of biodiversity is 121 extensive, after early skeptical attempts (Ghilarov 1996, Takacs 1996) the issue of the general 122 definition of biodiversity has not been subject to many in-depth conceptual analyses. It is 123 therefore useful to discuss the three classical approaches introduced above in more detail. 
126 This approach is predicated on the idea that a general definition of biodiversity can be based

127 on the notion of diversity, because the latter is a basic, simple and unequivocal notion.

128 Although it is implicitly accepted by many biologists, this approach has been rigorously

129 formalized only outside the ecological literature, by axiomatic economists (Bervoets \& Gravel

130 2007, Bossert et al. 2003, Gravel 2008, Klemish-Alhert 1993, Nehring \& Puppe 2002,

131 Weizman 1992) concerned to identify a general definition of "diversity", applicable to all

132 kinds of objects.

133 Given that the term "diversity" belongs to the ordinary language and seems to be simple and 134 unequivocal, it is natural to try to delineate its meaning by enlisting the properties naturally

135 associated with it. Axiomatic economists therefore start with lists of properties supposedly 136 naturally associated with the idea of diversity, from which they deduce definitions of 137 "diversity". For example, Pattanaik \& Xu $(1990,2000)$ claim that the properties inherent to 138 diversity are reflexivity, transitivity, cardinality, independence, monotony and indifference 139 (see Table 1 for formal definitions of these properties), and they show that richness is the only 140 property jointly satisfying them. Strictly speaking, what they demonstrate is that: if the 141 meaning of the term "diversity" is given by the properties above, then "diversity" is a 142 synonym of "richness".

143 Unfortunately, the identification of the relevant properties turns out to be less evident than it 144 seems. The monotony property provides a striking illustration of this idea, since the question 145 whether it should be considered a property inherent to diversity admits different answers 146 depending on the context. If formulated in terms of species, the idea that monotony is a 147 constitutive property of diversity roughly means that adding a species to a sample that does 148 not already contains it will always increase the diversity of the sample. This is intuitively 149 compelling in some contexts but, interestingly, some widely used measures of diversity, like 
150 the Shannon diversity index (Magurran 2004), do not satisfy this property. Indeed, this

151 measure has another intuitively compelling property, which happens to be incompatible with

152 monotony: it decreases when a species is added to a sample, if the population of this species is

153 markedly different from the populations of the other species in the sample (which is quite

154 often the case in real biological systems, for examples when invasive species invade native

155 communities). To take another specific example, Bervoets \& Gravel (2007) argue that another

156 idea is naturally associated with the notion of diversity. This idea is that, although most of the

157 time one can order differences between species (one can tell, for example, that the difference

158 between a human being and a pine is greater than the difference between a pine and a spruce),

159 it is sometimes impossible to tell how greater one difference between two species is than

160 another difference (although it is possible to quantify how greater the difference in DNA

161 sequences between a human being and a pine is than the one between a pine and a spruce, it is

162 impossible to make similar judgments when it comes to comparing overall differences). But

163 Bervoets \& Gravel (2007) demonstrate that, although this idea is arguably intuitively

164 associated with this idea of diversity, none of the usual diversity indices used in the literature

165 satisfy it; they show that the only conceivable index satisfying it is an otherwise

166 counterintuitive index that orders samples in terms of diversity on the sole basis of the

167 differences between the two most different species in each sample. In other words, what they

168 demonstrate is that, although this idea seems to be naturally associated with the notion of

169 diversity in some contexts, a more precise investigation shows that it is impossible to adhere

170 to this idea consistently. Similarly, for each and every property claimed to be intuitively

171 inherent to diversity, intuitive examples can be found to argue that it is not (and a substantial

172 part of the axiomatic literature actually consists in exploiting such examples).

173 The axiomatic literature on diversity has thereby produced a whole series of axiomatic

174 definitions of diversity, each equating the putative property diversity with different 
175 conjunctions of elementary properties (Gravel 2008, Meinard 2011). These various analyzes

176 are all based on intuitively compelling examples, but their respective results are markedly

177 different from one another (Aulong et al. 2005). This would not have disastrous implications,

178 if the whole axiomatic approach to diversity were not based on the assumption that diversity

179 is a basic, simple and unequivocal notion. The very fact that axiomatic studies do not clearly

180 converge on a simple, unequivocal analysis of the notion of diversity therefore demonstrates

181 that the fundamental postulate of this approach that diversity is a basic, simple and 182 unequivocal notion, is unwarranted.

183 This failure of the ordinary approach therefore shows that, apart from vague intuitions, there

184 is no firm criterion to decide which properties are really inherent to the notion of diversity

185 (and the same is obviously true of the notion used as synonyms of "diversity" in the CBD 186 definition and its reformulations, like "variety", "variability"). In other words, although the 187 term "diversity" seems clear and unequivocal, it is in fact deeply ambiguous. As a 188 consequence, all the definitions of biodiversity that - like the CBD definition and many of its 189 reformulations - contain the term "diversity" are doomed to be ambiguous themselves.

\subsection{The conventionalist approach}

192 This alternative approach has been prominently developed by Sarkar $(2002,2005)$. Sarkar

193 does not explicitly criticize the ordinary approach, but his emphasis on the need to develop a

194 radically new approach, rejecting supposedly transparent terms like "diversity" or

195 "variability", shows that he implicitly admits that the CBD definition and its reformulations

196 based on ordinary terms are unsatisfactory.

197 At the core of his alternative approach lie two questionable postulates. P1: Biodiversity is

198 confined to conservation biology. P2: Conservation biology is only concerned with ranking 199 series of natural areas in terms of priority for conservation. The fact that Sarkar admits these 
200 postulates (at least for the purpose of defining "biodiversity") is clearly stated in his 201 contention that "biodiversity should be ... defined as what is optimized by the place 202 prioritization procedures" (Sarkar 2005, p. 180), the latter procedures in turn being the pivotal 203 tool of his "consensus view of conservation biology" (see his Table 6.1.1, page 153, and more 204 generally his whole chapter 6). Sarkar then defines different "surrogates" (Heyer et al. 1994) 205 representing biodiversity in various ways (Fig. 1A). "Estimator surrogates", such as species 206 composition, are components of biodiversity that can be directly measured. These estimator 207 surrogates are estimator variables having "true surrogates" as their objective variables, and 208 true surrogates are loosely defined as having biodiversity as their "intended objective". 209 Associated with postulates P1 and P2, these definitions of surrogates allow Sarkar to claim 210 that any place prioritization algorithm based on estimator surrogates implicitly defines 211 biodiversity.

212 The construction and implementation of such algorithms always involves making choices that 213 cannot be entirely justified. For example, when one chooses between using species richness or 214 sub-species richness as index, although this choice can be partially justified, it also involves a 215 modicum of arbitrariness. Since different algorithms can rank differently the same series of 216 places, this approach therefore yields a highly unstable definition of biodiversity. This 217 instability is relatively innocuous so long as one accepts the postulates of his approach. 218 However, it appears to be a serious problem as soon as one realizes that these postulates, 219 especially P1 (that biodiversity is confined to conservation biology), are hardly credible. 220 Indeed, the term "biodiversity" has recently undergone a striking interdisciplinary expansion 221 and is now a key-notion in several other biological disciplines, especially in functional 222 ecology (Loreau et al. 2002, Hooper et al. 2005) and biogeography (Brooks \& McLennan 223 2002). Its economic (Heal 2004), social and cultural importance is also increasingly 224 recognized, and biodiversity has become a crucial theme in economics of ecosystem services 
(Perrings et al. 2009) and ethics (Maris 2010). One could therefore draw a surrogacy structure

226 for each relevant discipline neglected by Sarkar, each leading to another implicit definition of

227 biodiversity. MacLaurin \& Sterelny (2008) take Sarkar's approach to be generalizable in this

228 way, which they summarize by saying that "Sarkar uses 'biodiversity' to mean whatever we

229 think is valuable about a biological system" (p. 8). We would more precisely say that

230 according to Sarkar's generalized approach, in each and every case where something is

231 deemed valuable in a biological system, this something can be used to produce a new,

232 idiosyncratic definition of "biodiversity" (Fig. 1B). In this approach, trying to find a general

233 definition to "biodiversity" is therefore futile, because each trial is doomed to produce another

234 definition, neither better nor worse than former ones. For example, the application of a given

235 prioritization algorithm for conservation purposes to a given series of places would produce a

236 first definition, the application of a different procedure to make a public choice in the

237 management of fisheries would give a second definition, and the application of another

238 approach to a carbon storage scheme would give a third definition. The three definitions,

239 associated as they would be with different reasons for valuing the corresponding biological

240 systems, would equally qualify as definitions of biodiversity.

241 The deflationary flavor of this approach would certainly make it hardly credible for most

242 biologists. However that might be, from the point of view of our inquiry in this article, the

243 main problem with this conventionalist approach is that it cannot explain the nature of the link

244 between the various specialized biodiversity disciplines.

2.3. The unit-and-differences approach

247 Maclaurin \& Sterelny (2008) have developed an original approach (to some extent prefigured 248 in Gaston 1996), which we call, borrowing their own phrase, the "unit-and-differences" 249 approach. Their argument can be summarized in four steps: 
250 (1) "In general, the diversity of a system will depend both on the number of distinct elements 251 in the system and on their degree of differentiation." (p. 9)

252 (2) The identification of the distinct elements of a system and their differences is not arbitrary 253 from a scientific point of view. On the contrary, it is "central to any attempt at understanding 254 a domain ... because a good system of classification links diagnostic criteria for identification 255 with similarity in causal profile." (p. 10) In other words, assuming that scientific theories are 256 mainly devoted to identify and characterize causal relations, their capacity to fulfill this 257 central aim is crucially linked with their capacity to identify the distinct elements of a system 258 and their differences.

259 (3) Since "history, environment and chance ... affect their causal profile in different ways ... it 260 turns out that there is no single system for identifying all the similarities and differences 261 between biological systems that matter." (p. 10)

262 (4) The characterization of any given biological system in terms of biodiversity therefore 263 depends on the theoretical approach chosen to study it, which in turn depends on "the 264 instrumental and explanatory purposes of particular groups of scientists” (p. 21)

265 From this reasoning, Maclaurin \& Sterelny conclude that biodiversity is "a natural magnitude 266 (or magnitudes) of biological systems" (p. 6), that cannot be reduced to "a single natural 267 property" (p. 7) but for which "a phylogenetically informed species count is a good general 268 indicator or surrogate" (p. 7). On the face of it, this definition seems quite similar to the 269 general definitions used by most biologists (see the examples cited in the introduction, and in 270 Gaston 1996). It differs, however, in that: (1) It explicitly emphasizes that the search for a 271 unified measure is hopeless (which is why this approach is characterized as "pluralist" by its 272 authors). And (2), it explains this exclusion of a unified measure by an epistemological 273 account of the reason why different scientific explanations of a given biological system can 274 differ in the units, differences and dissimilarities that they deem important ("we need to 
275 identify diversity differently, for different explanatory projects”, Maclaurin \& Sterelny 2008, 276 p. 8).

277 This approach is arguably the most promising of the current approaches since, contrary to the 278 other two, it is not marred by any obvious flaw. However, we will argue in the following 279 section that it shares with the other two approaches two unwarranted tenets. And we will 280 argue, in section 4, that relaxing these two tenets allows developing an alternative approach 281 that we believe is even more powerful than the unit-and-differences one.

\section{A new constructivist approach toward a general definition of biodiversity}

The first step to develop a new fourth approach is to realize that the logic of these classical approaches is based on two hidden unsupported tenets.

\subsection{Two tenets presupposed by the three classical approaches}

The first tenet $\left(\mathrm{T}_{1}\right)$ is the presupposition that the definition of a term, understood as what we are trying to capture by our act of defining it, cannot be determined by this act itself. In short,

291 the definition of a term always preexists our act of defining it. The second tenet $\left(\mathrm{T}_{2}\right)$ is that 292 finding the definition of a term is a matter of identifying an entity, in the objective world, to 293 which the term would refer. Here "entity" should be understood broadly, encompassing not 294 only things and objects, but also processes, properties and attributes. In the philosophical 295 literature, the two tenets $T_{1}$ and $T_{2}$ constitute the "semantic postulate" (Tughendhat 1976, 296 Meinard 2011). First, let us show that the three classical approaches presented above are 297 indeed based on these tenets. Then we will show that, although these two tenets seem to be 298 self-evidently valid, convincing counter-examples show that they are false. 
Most obviously, the ordinary approach is predicated on $T_{1}$ and $T_{2}$. Indeed, in this approach,

300 there is such a thing as the preexisting meaning of the term "diversity" $\left(\mathrm{T}_{1}\right)$, given by the

301 alleged fact that this term would refer to a preexisting property or list of properties $\left(\mathrm{T}_{2}\right)$.

302 Similarly, as quoted above, the unit-and-differences approach explicitly claims that 303 "biodiversity" refers to "a natural magnitude (or magnitudes) of biological systems" 304 (Maclaurin \& Sterelny 2008, p. 6), and therefore explicitly assumes $T_{1}$ and $T_{2}$. Although it 305 does not accept it so openly, the conventionalist approach is also demonstrably predicated on $306 T_{1}$ and $T_{2}$, since it is based on an inference whose validity is predicated on $T_{1}$ and $T_{2}$. Indeed, 307 from the premise $\left(\mathrm{P}_{\mathrm{c}}\right)$ that various entities emerge as what is optimized by various algorithms, 308 the conventionalist approach concludes $\left(\mathrm{C}_{\mathrm{c}}\right)$ that general definitions of biodiversity are 309 doomed to be elusive. But $\mathrm{C}_{\mathrm{c}}$ does not follow from $\mathrm{P}_{\mathrm{c}}$ alone. It only follows if $\mathrm{P}_{\mathrm{c}}$ is associated 310 with $\mathrm{T}_{1}$ and $\mathrm{T}_{2}$. Therefore, the three classical approaches appear to be based on the two tenets $311 \mathrm{~T}_{1}$ and $\mathrm{T}_{2}$, but these two tenets are questionable. $\underline{\text { of defining it }}$

315 In order to establish that $T_{1}$ is false, the example of the term "art" is peculiarly useful. This is meant to convey neither the idea that biodiversity is an aesthetic notion, nor the one that conserving and defining biodiversity are artistic endeavors. The analogy is limited to the role

318 played by these notions in our language.

319 In a sense, we all know what "art" means, but the question of a precise definition of the term 320 is notoriously indecidable. Several approaches have been developed. They share some 321 similarities with the approaches of biodiversity studied above, but are not exactly identical.

322 Purely empirical approaches attempt to define art by identifying what people typically call 323 "art" (Kennick 1958, Weitz 1956). Essentialist approaches claim they can identify once and 
324 for all the essence of art (Danto 1981). Lastly, noticing that innumerable heterogeneous 325 human activities involve art, demystifying approaches claim that there is no such thing as art 326 in general (Gaut 2000).

327 The history of art theorizing illustrates the failure of all these three classical approaches: 328 artists usually respond to each and every definition of art by modifying their artistic practices 329 (Pignocchi 2012). Indeed, a given definition can shed light on hitherto neglected aspects of art 330 and thereby launch creative processes aimed at illustrating or contradicting it, and new 331 definitions are needed to make sense of the emerging result. In that sense, practices and 332 corresponding theories co-evolve in possibly endless parallel evolutions. Contrary to what $\mathrm{T}_{1}$ 333 claims, the definition of the term is not independent of theorists' attempts at defining it: it is 334 not preexisting. However, the fact that no definitive definition of art may ever be reached does 335 not mean that trying to define "art" is wishful thinking. Quite the contrary, it means that 336 striving to define art is taking part in the construction of art itself (for another example, 337 illustrating that a rejection of $\mathrm{T}_{1}$ is not confined to aesthetic issues, see Dworkin's (1998) 338 approach to law). an entity

342 It might seem at first sight that a term cannot be meaningful at all if it cannot be defined as 343 referring to a preexisting entity. However, some very common terms, undoubtedly 344 meaningful, do not function like this. The term "hello" is an apt example. If one were pressed 345 to define this term, it would be pointless to strive to identify an entity to which the term would 346 refer. One had better try to identify the role played by the term in our language: "hello" is 347 used to greet, and there is nothing more to say to define the term (Searle 1969). 
348 However, this example of the term "hello" might seem irrelevant to an inquiry into the 349 meaning of "biodiversity" because, contrary to "biodiversity", it is not a noun. But an 350 approach paralleling the one to "hello" proves to be fruitful in the case of numerous nouns as 351 well. Think about the noun "legitimacy": trying to identify the role it plays in our language is 352 undoubtedly a more promising route to define it than pretending to identify an entity to which 353 it would refer.

354 This approach to definitions, according to which defining a term is first and foremost a matter 355 of identifying what the term is useful for (rather than what it refers to), originates in the work 356 of Wittgenstein (2001) and Austin (1975), and has been developed by the school of ordinary 357 language philosophy (Soames 2003) and other so-called pragmatic linguists (Szabò 2006).

358 Identifying the role played by terms like "hello" in our language is obviously easier than 359 identifying the role played by terms like "biodiversity". However, the philosophical 360 arguments articulated above show that rigorously defining the term "biodiversity" is not 361 necessarily identifying an entity (be it a set a objects, processes, properties or magnitudes) to 362 which the term would refer nor providing for a definitive formula. It is rather scrutinizing 363 what kind of role the notion plays in our language, assessing if it is useful at all, and if it is, 364 eventually showing what it is useful for. Since, in this approach, using the term "biodiversity" 365 and trying to define it are taking part in the construction of the concept itself, we call this 366 approach "constructivist".

4. The key-question of the constructivist approach: what is the general notion of biodiversity useful for?

370 In order to illustrate how our constructivist approach works and how useful it can be, let us 371 see what help it can provide in a practical example of valuation: the fishery in the Aleutian 372 marine ecosystem studied by Estes et al. (1998), Finnoff \& Tschirhart (2003) and Eichner \& 
373 Tschirhart (2007), among others (Fig. 2). According to standard economics, fisheries and

374 associated ecosystems face several problems of externalities (Perrings 2009). In what follows,

375 we will focus on one of them: the risk that repercussions of the overexploitation of one

376 resource are not being taken into account in the determination of consumers' behavior. In the

377 example chosen, human consumers buy items of one species (pollock) on markets and thereby

378 indirectly impact other species due to interactions in the ecological system. This indirect 379 impact can in turn alter the provision of various ecological services. Most variants of this 380 problem, and the alleged solutions provided by the standard economic approach, are 381 articulated in terms of "biodiversity" in most publications. The first step of the constructivist 382 approach is to ask if this formulation makes any difference. If it does, this means that the term 383 "biodiversity" plays a role (or, equivalently, has a function) in these discourses, and the 384 second step of a constructivist approach is then to use this function. If it turns out that this 385 two-steps procedure is feasible and can be generalized, just like we illustrate a definition of 386 "hello" by greeting people, we will have produced a definition of "biodiversity" by showing 387 what the general notion of biodiversity is useful for. and if so, identify it

391 According to standard economics, if ecologists and economists manage to condense all the information contained in the ecological network into an increase of the price of pollock (for example through taxes imposed on harvesting activities or a cap on harvest), demand will

394 drop, overfishing will cease, kelp will recover, etc. (Finnoff \& Tschirhart 2003). This 395 conclusion could be articulated in economic terms alone, but as a matter of fact economists 396 often make the effort to translate it in terms of "biodiversity". 
397 If either the conventionalist or the unit-and-difference approach were true, as explained 398 above, it would mean that, when an economist says "biodiversity", what she or he has in mind 399 is entirely determined by purely economic concepts (utility functions, social planner's 400 optimization and the like), and is completely different from what an ecologist has in mind 401 when using the same term. In its application to the economic problem at issue here, this idea 402 is patently implausible. Indeed, economists would not bother translating their results in terms 403 of "biodiversity" if the only expected result were to translate the message from one jargon 404 accessible only to economists, to another jargon just as much esoteric. If economists so 405 forcefully insist on translating their results in terms of "biodiversity", it can only be because 406 they tacitly claim that their results are relevant for other biodiversity sciences. This point, 407 regrettably ignored by the classical approaches to the general definition of biodiversity 408 (including the most promising unit-and-difference approach), can be generalized to all 409 discourses articulated in terms of "biodiversity". As soon as one expresses or translates one's 410 disciplinary discourse in the general terms of "biodiversity", one claims (or at least one is 411 committed to claim) that what one says is relevant beyond one's own disciplinary borders412 relevant for all the other disciplines making, as a matter of fact, similar credible claims.

413 But a claim (emitted by one or several speaker(s)) is always directed at one or several 414 hearer(s), and is predicated on its acceptability by this audience (Habermas 1981). For 415 example, if speaker S utters "I am the Commander of this crew", this utterance cannot qualify 416 as a claim properly speaking if $\mathrm{S}$ is alone in the desert or if he is one ordinary seaman among 417 others in the crew he speaks to: in such cases S's utterance is a vain one (or a joke). It cannot 418 be a claim properly speaking unless $\mathrm{S}$ utters it before a crew that is liable to accept it (which 419 can be the case, e.g., if the real commander is no longer able to honor his duty and $\mathrm{S}$ is the 420 second-highest ranked official). A more comprehensive reformulation of the constructivist 421 idea is therefore: for the speaker (or writer), the function of the term "biodiversity" is to claim 
general relevance of his results; for the hearer (or reader or analyst), it is to critically assess the credentials of this purported relevance of the results.

\subsection{The second step of the constructivist approach: use the function of the term}

If implemented in the case of ecological-economic modeling, the constructivist approach thus holds that using the term "biodiversity", and thereby constructing its definition, is asking the question: do the results of ecological economic models qualify as relevant, beyond economics alone, to all biodiversity disciplines?

\subsubsection{Disciplinary assumptions}

One important issue to assess this putative relevance is whether the basic assumptions postulated by these models can be taken for granted in a more general context. Typically, these studies postulate that it is possible to achieve a perfect knowledge of the ecological mechanisms and that the behavior of the economic agents can be perfectly foreseeable (and modeled by a utility function). One problem created by these assumptions is that the models based on them prescribe to concentrate and confine all the relevant information into prices, which in turn incites consumers to think only about their own money. Take for example the detrimental effects of the production, commercialization and usage of marketed products on insect pollinators and the ensuing ecological consequences (Gallai et al. 2009). If all these detrimental effects were already integrated in their price, there would be no need for consumers to think about anything else than prices: seeing that prices are high, they would eschew buying these products and the detrimental effects would thereby be avoided. In this scenario, consumers would not need to know that the reason why the price of a given product is high is that it has detrimental effects on pollinators, and it would therefore be unnecessary for ecologists and economists to invest time and money to diffuse ecological information. 
447 Similarly, consumers would not need to adapt their preferences to the environmental constraints and to organize their decision-making in an intelligent, long-term horizon (Singer 2004).

450 If only the prospect of ever being able to integrate into prices all the ecological information, 451 concerning all the ecological mechanisms all around the world, were a credible one, it might 452 be worth investigating this strategy. Unfortunately, it is widely acknowledged that this 453 prospect is an unachievable, fanciful one (Barbier 2000): in the real world, perfect knowledge 454 is unachievable even for the best scientists and prices therefore cannot integrate all the ecological information. The optimum calculated by the model being unachievable, the latter faces a so-called "problem of the second best" (Lipsey \& Lancaster 1956-57): there is no 457 logical guarantee that acting as if the optimum were achievable (that is to say: endorsing the 458 standard assumptions and thereby promoting the creation of incentives for consumers to 459 develop a self-centered, short-sighted and uninformed behavior) will be conducive to the second best result. It is possible that achieving the second best requires a completely different 461 strategy, for example that consumers precisely do not behave in a self-centered, short-sighted 462 and uninformed way. Therefore, although the standard economic approach is undoubtedly 463 valid within the framework defined by its disciplinary assumptions, it could have very 464 destructive effects if other biodiversity disciplines were to mistake the standard economic results as being applicable to the real world (whereas, due to the problem of the second best, 466 they are in fact only applicable to fictitious worlds where the optimum is achievable).

467 When using the term "biodiversity" in presenting their results, economists claim that their 468 results are relevant outside their discipline; but using the term "biodiversity" as critical 469 readers of these economic arguments, we see that this claim must be rejected. This example 470 thus illustrates that taking seriously the implicit claims of generality encapsulated in the term 471 "biodiversity" and critically assessing its credentials is a very rewarding exercise, because it 
472 shows why disciplinary approaches can fail to solve integrated, interdisciplinary biodiversity

473 issues all by themselves, and where and why they are flawed. As additional illustrations of

474 this heuristic role we proceed by showing that the constructivist approach can shed light on

475 three crucial components of the biodiversity issues presented in the fishery example that are

476 obscured by the standard economic approach.

477

478

479

480

481

482

483

484

485

486

487

488

489

490

491

492

493

494

495

\subsubsection{What counts as a solution?}

What if consumers were willing to pay the increased price calculated according to standard economics, and thereby go on impacting the environment? Clark (1999) showed that, if this possibility is admitted, it can be economically rational to exploit species to extinction. However, the latter case is ignored without justification in most current models. For example, Eichner \& Tschirhart (2007) simply state, in a foot-note, without any explanation: "[t]he question of optimal extinction is beyond the scope of the present paper" (note 15, p. 744). If "optimal extinction" is a solution to the management problem under standard economics, why then does it ignore it? The constructivist approach suggests that the reason is that, in practice, standard economics theorists vaguely see that optimal extinction cannot qualify as a solution in the context of an interaction between economics and other biodiversity disciplines. The very fact that these studies present themselves as economic studies of biodiversity constrains the kind of result that they can present as genuine solutions more strongly than if they would simply present themselves as economic studies of entities that happen to be independently called "biodiversity" by biologists. 
496 Conveniently enough, the neglect of optimal extinctions also makes it look as though 497 ecological-economic modeling is a purely scientific, value-neutral exercise. But as soon as 498 one accepts that such problems might empirically arise, it becomes clear that standard 499 economics makes two incompatible moral claims. On the one hand, standard economics 500 postulates that ecological and economic experts are justified to manipulate prices, and thereby 501 people's behavior. This claim is undeniably a moral one, and consistently maintaining it 502 would imply that experts should be the only ones to take the rein of ecosystem management. 503 But supporters of standard economics forcefully reject this implication, since their models are 504 based on the idea that, so long as ecological consequences are integrated in prices, consumers 505 should be authorized to act freely on markets. In that sense, they admit that experts cannot 506 simply take all the decisions on behalf of the larger society (Estlund 2008). At the very least, 507 economic methods have to admit the moral status of these premises, and to clarify them.

\subsubsection{Qualitative information and the formation of preferences}

510 By positing that consumers should act freely on markets, standard economics thus assumes

511 that consumers' and citizens' preferences must somehow be taken into account and respected 512 (Sen 1973). This undeniably moral premise is, in one form or another, shared by the vast 513 majority of the current philosophical (Kymlicka 2002) and economic (Sen 2008) literature,

514 and is hence arguably not very controversial. Our critical examination of the application of 515 standard economics to the fisheries issue however suggests that the internal coherence of 516 ecological-economic models in their endorsement of this premise is doubtful. Indeed, if one 517 decides to respect preferences, one has to make sure that the preferences purportedly 518 respected are conveniently formed. Ecological-economic models will therefore remain 519 internally incoherent so long as they do not investigate whether, in addition to or instead of 520 the integration of ecological information into prices, the very construction of preferences 
requires that consumers understand the concrete ecological consequences of their acts, evaluate them with regard to the values they hold, and thereby make reflexive choices (Sagoff 2008, Meinard \& Grill 2011).

525 Altogether, our critical analysis in this section does not mean that economics is irrelevant to

526 the resolution of biodiversity issues. It simply shows that, as they stand, these approaches do

527 not live up to the expectations aroused by the formulation of their results in terms of "biodiversity". But if standard economists take seriously and endorse our constructivist approach, this demonstration of their failure can turn into the first step of a fruitful critical 530 dialog. Indeed, a simple clarification and open admission by economists of the various 531 presuppositions of their approaches would already considerably strengthen the quality of 532 collaborations between economists and biologists. This could be the first step towards collaborations through which economists and biologists could participate in a reorientation of

534 economic models liable to make the latter more relevant to the resolution of environmental 535 issues.

536 Besides, although our explanation in this article has been centered on an example of 537 interactions between economics and ecology, the logic elaborated above is applicable to the 538 other interdisciplinary interactions as well. For example, just like economic studies, 539 anthropological studies presenting themselves as studies of biodiversity thereby implicitly 540 claim that they are relevant to the other biodiversity studies, outside anthropology. Contrary to 541 economic studies, most of these studies openly acknowledge that they are not ethically 542 neutral, for example, when they (more or less openly) promote an approach in which local 543 stakeholders take the reins of environmental management (e.g. Mougenot 2003). But they do 544 not investigate whether, and to what extent, their specific ethical stances can constrain the 
545 possibility for them to participate, on a par with ecological studies, to the resolution of 546 common problems.

547 And what is true of interactions between disciplines is also true of interactions between 548 scientists and political decision makers. According to our constructivist approach, these 549 interactions could be considerably enriched if, instead of postulating that "biodiversity" must 550 refer to a supposedly clearly identified entity, both scientists and decision makers were to 551 admit that talking about "biodiversity" to one another commits them to engage in a 552 collaborative process of clarification of the problems they wish to solve.

\section{Conclusions}

555 Many authors are prone to emphasize the interdisciplinary status of the concept of 556 biodiversity, or to stress that it is a "bridge concept" (Norton 2008) liable to link scientific 557 practices and public discourse. But the possibility for this notion to be a bridge concept requires a comprehensive explanation. Our explanation in this article is based on the idea that

559 the term "biodiversity" does not refer to a pre-existing entity: its meaning is given by its 560 function in our language, and this function is not primarily a referential one. The function of 561 the term "biodiversity" is the following: it is a term used to present results, ideas and projects 562 in such a way as to claim that they are relevant, beyond their home discipline, to all the 563 disciplines and discourses that happen to use the term. In this approach, biodiversity is a 564 bridge concept indeed, because its function in our language is such that, using the term 565 "biodiversity" commits the user to claim, and to be able to redeem her or his claim, that what 566 she or he says about biodiversity is relevant for the other users of the term.

567 When an ecologist is done with the purely ecological part of the study of an ecological568 economic system, the easiest way for her or him to proceed is to hand over the case to an 569 economist who will study it independently. In our rationale, the interdisciplinary study of 
biodiversity is not that kind of relay race. It is rather an attitude that consists in taking

571 advantage of insights from as many disciplines as possible to shed light on basic problems or presuppositions in order to constructively criticize them.

573 This form of interdisciplinarity, that is according to our logic a crucial part of the agenda of

574 the Intergovernmental Science-Policy Platform on Biodiversity and Ecosystem Services 575 (IPBES), is not an easy task. It involves tackling the notion of biodiversity in a truly integrative way, critically assessing the scientific credentials of various accepted methods, and confronting the novelty of the environmental challenges. Our approach hence suggests that biodiversity sciences have a philosophical and societal relevance, and that biologists should not be afraid to take a more affirmative stance and to engage more vigorously in the

580 resolution of biodiversity issues - be it by critically appraising current valuation methods, participating in the diffusion of ecological knowledge, invigorating philosophical and political debates, or engaging in the creation of relevant institutions.

\section{Acknowledgements}

585 We wish to thank the two reviewers of Ethics, Policy \& Environment for their numerous

586 comments and powerful suggestions. This work was supported by a grant from the Fondation 587 pour la Recherche sur la Biodiversité (FRB). For their comments and corrections, we wish to 588 thank H. Le Guyader, O. Petchey, M. Hall, M. Meinard, P. Castets and A. Pignocchi, as well 589 as J.-S. Gharby, P. Grill, A. Lapied, J. Magnan de Bornier, M. Orillard and G. Tosi.

\section{$591 \quad$ References}

592 Aulong, S., Erdlenbruch, K., Figuières, C. 2005. Un tour d'horizon des critères d'évaluation 593 de la diversité biologique. Economie Publique 16: 3-46. 
Austin, J.L. 1975. How To Do Things With Words. Harvard University Press, Cambridge (Mass.).

596

598

Barbier, E.B. 2000. Valuing the environment as input: review of applications to mangrovefishery linkages. Ecological Economics 35: 47-61.

Bervoets, S., Gravel, N. 2007. Appraising diversity with an ordinal notion of similarity: an axiomatic approach. Mathematical Social Sciences 53: 259-273.

Bossert, W., Pattanaik, P.K., Xu, Y. 2003. Similarity of options and the measurement of diversity. Journal of Theoretical Politics 15: 406-421.

Brooks, D. R., McLennan, D.A. 2002. The Nature of Diversity. University of Chicago Press, Chicago.

Clark, C.W. 1999. Renewable resources: fisheries. In van der Bergh, J.C.JM. (ed) Handbook of Environmental and Resource Economics, second edition. John Wiley and sons, New York.

Colyvan, M., Linquist, S., Grey, W., Griffiths, P., Odenbaugh, J, Possingham, H.P. 2009. Philosophical issues in ecology: recent trends and future directions. Ecology and Society $14: 22$

Danto, A.C. 1981. The Transfiguration of the Commonplace. Harvard University Press, Cambridge (Mass.).

Eichner, T., Tschirhart, J. 2007. Efficient ecosystem services and naturalness in an ecological/economic model. Environmental and Resource Economics 37: 733-55.

Estes, J.A., Tinker, M.T., Williams, T.M., Doack, D.F. 1998. Killer whale predation on sea otters linking oceanic and nearshore ecosystems. Science 282: 473-476. 
616 Estlund, D. 2008. Democratic Authority. Princeton University Press, Princeton.

617 Faith, D. P. 1992. Conservation evaluation and phylogenetic diversity. Biological 618 Conservation 61: 1-10.

619 Finnoff, D., Tschirhart, J. 2003. Harvesting in an eight species ecosystem. Journal of $620 \quad$ Environmental Economics and Management 45: 589-611.

621 Fleishman, E., Noss, R.F., Noon, B.R. 2006. Utility and limitations of species richness 622 metrics for conservation planning. Ecological Indicators 6: 543-553.

623 Furubotn, E.G., Richter, R. 2005. Institutions and Economic Theory. Second Edition. The 624 University of Michigan Press, Ann Harbour.

625 Gadamer, H.-G. 2004. Truth and Method. Continuum Publishing Group, London.

626 Gallai, N., Salles, J.-M., Settele, J., Vaissières, B.E. 2009. Economic valuation of the 627 vulnerability of world agriculture confronted with pollinator decline. Ecological $628 \quad$ Economics 68: 810-821.

629 Gaston, K.J. (ed) 1996. Biodiversity: A Biology of Numbers and Differences. Blackwell, $630 \quad$ Malden.

631 Gaut, B. 2000. Art as a Cluster Concept. In Carroll, N. (ed). Theories of art today. University 632 of Wisconsin Press, Madison.

633 Ghilarov, A. 1996. What does "biodiversity" mean? Scientific problem or convenient myth? 634 Trends in Ecology and Evolution 11:304-306.

635 Gravel, N. 2008. What is diversity? In Boylan, T.A., Gekker, R. (ed). Economics, Rational 636 Choice and Normative Philosophy. Routledge, New York. 
637 Groves, C., Jensen, D. et al. 2002. Planning for biodiversity conservation: Putting 638 conservation science into practice. BioScience 52 (5): 499-512.

639 Habermas, J. 1981. Theorie des kommunikativen Handelns. Suhrkamp, Frankfurt am Main.

640 Habermas, J. 1983 Moralbewusstsein und kommunikatives Handeln. Suhrkamp, Frankfurt am 641 Main.

642 Heyer, W. R., Donnelly, M. A., McDiarmid, R. W., Hayek, L. A. C., Foster M. S. 1994. 643 Measuring and monitoring biological diversity: standard methods for amphibians. 644 Smithsonian Institution Press, Washington, D.C.

645 Heal, G. 2004. Economics of biodiversity: an introduction. Resource and Energy Economics 646 26: $105-114$.

647 Hooper, D.U., et al. 2005. Effects of biodiversity on ecosystem functioning: a consensus of 648 current knowledge. Ecological Monographs 75: 3-35.

649 Kennick W. E. 1958. Does traditional aesthetics rest on a mistake? Mind 67: 317-334.

650 Klemisch-Ahlert, M. 1993. Freedom of choice: a comparison of different rankings of 651 opportunity sets. Social Choice and Welfare 10: 189-207.

652 Kymlicka, W. 2002. Contemporary Political Philosophy. Oxford University press, Oxford.

653 Lewis, D. 1969. Convention. Harvard University Press, Cambridge (Mass.).

654 Lipsey, R.G., Lancaster, K.J. 1956-57. the General Theory of the Second Best. Review of $655 \quad$ Economic Studies 24: 11-32.

656 Loreau, M. 2010. The Challenges of Biodiversity Sciences. Excellence in Ecology 17. 
657 Loreau, L., Naeem, S., Inchausti, P. (ed). 2002. Biodiversity and Ecosystem Functioning: 658 Synthesis and Perspectives. Oxford University Press, Oxford.

659 Mace, G.M., Norris, K., Fitter, A.H. 2012. Biodiversity and ecosystem services: a 660 multilayered relationship. Trends in Ecology and Evolution 27(1): 19-26.

661 Maclaurin, J., Sterelny, K. 2008. What is Biodiversity? The University of Chicago Press, $662 \quad$ Chicago.

663 Magurran, A.E. 2004. Measuring Biological Diversity. Blackwell, Malden.

664 Maris, V. 2010. Philosophie de la biodiversité. Buchet Chastel, Paris.

665 Mason, N.W.H., MacGillivray, K., Steel, J.B., Wilson, J.B. 2003. An index of functional 666 diversity. Journal of Vegetation Science 14: 571-8.

667 Meinard, Y. 2011. L’expérience de la biodiversité. Hermann, Paris.

668 Meinard, Y., Grill, P. 2011. The Economic Valuation of Biodiversity as an Abstract Good. $669 \quad$ Ecological Economics 70: 1707-1714.

670 Mougenot, C. 2003. Prendre soin de la nature ordinaire. Édition de la Maison des Sciences de 671 l'Homme, Paris.

672 Nehring, K., Puppe, C. 2002. A theory of diversity. Econometrica 70: 1155-1198.

673 Norton, B.G. 2005. Sustainability. The University of Chicago Press, Chicago.

674 Norton B.G. 2008. Toward a policy-relevant definition of biodiversity. In Askins, R.A., 675 Dreyer, G.D., Visgilio, G.R., Whitelaw, D.M. (ed). Saving Biological Diversity. Springer, $676 \quad$ New York. 
677 Noss, R. F. 1990. Indicators for monitoring biodiversity: a hierarchical approach. $678 \quad$ Conservation Biology 4: 355-364.

679 Pattanaik, P.K., Xu, Y. 1990. On ranking of opportunity sets in terms of freedom of choice. $680 \quad$ Recherches Economiques de Louvain 56: 383-90.

681 Pattanaik, P.K., Xu, Y. 2000. On diversity and freedom of choice. Mathematical Social $682 \quad$ Science 40: 123-130.

683 Perrings, C. 2009. Biodiversity conservation in sea beyond national jurisdiction: the economic 684 problem. In Ninan, K.N. (ed). Conserving and Valuing Ecosystem Services and 685 Biodiversity. Earthscans, London.

686 Perrings, C., et al. 2009. The economics of biodiversity and ecosystem services. In Naeem, S., 687 Bunker, D.E., Hector, A., Loreau, M., Perrings, C., editors. Biodiversity, Ecosystem 688 Functioning, and Human Wellbeing. Oxford University Press, Oxford.

689 Petchey O.L., Gaston, K.J. 2002. Functional diversity (fd), species richness, and community $690 \quad$ composition. Ecology Letters 5: 402-11.

691 Petchey, O.L., O’Gorman, E.J., Flynn, D.F.B. 2009. A functional guide to functional diversity 692 indices. In Naeem, S., Bunker, D.E., Hector, A., Loreau, M., Perrings, C., editors. 693 Biodiversity, Ecosystem Functioning, and Human Wellbeing. Oxford University Press, 694 Oxford.

695 Pignocchi, A. 2012. L'œuvre d'art et ses intentions. Odile Jacob, Paris.

696 Purvis, A., Hector, A. 2000. Getting the measure of biodiversity. Nature 405, 6783.

697 Sagoff, M. 2008. The Economy of Earth, Second Edition. Cambridge University Press, 698 Cambridge (Mass.). 
Sarkar, S. 2002. Defining ‘biodiversity’, assessing biodiversity. Monist 85: 131-155.

700

701

702

703

704

705

706

707

708

709

710

711

712

Sarkar, S. 2005. Biodiversity and Environmental Philosophy. Cambridge University Press, Cambridge (Mass.)

Schläpfer, F., Schmid, B., Seidl, I. 1999. Expert estimates about effects of biodiversity on ecosystem processes and services. Oikos 84: 346-52.

Schleuter D., Daufresne M., Massol F., Argillier C. 2010. A user's guide to functional diversity indices. Ecological Monographs 80: 469-484.

Searle, J.R. 1969. Speach Acts. Cambridge University Press, Cambridge (Mass.).

Sen, A.K. 1973. Behavior and the concept of preference. Economica 40: 241-259.

Sen, A.K. 2009. The Idea of Justice. Penguin Books, London.

Singer, P. 2004. One World. Yale University Press, New Haven.

Soames S. 2003. Philosophical Analysis in the Twentieth Century. Princeton University Press.

Szabò, Z.G. 2006. The Distinction between Semantics and Pragmatics. In Lepore, E., Smith, B.C. (ed) The Oxford Handbook of Philosophy of Language. Oxford University Press, Oxford.

Takacs, D. 1996. The Idea of Biodiversity. John Hopkins University Press, Baltimore.

Tassy, P. 2006. Biodiversité. In Lecourt, D., editor. Dictionnaire d'histoire et de philosophie des sciences. Presses Universitaires de France, Paris.

Tughendhat, E. 1976. Vorlesungen zur Einführung in die sprachanalytische Philosophie. Suhrkamp, Frankfurt am Main. 
720 Weitz, M., 1956. The Role of Theory in Aesthetics. Journal of Aesthetics and Art Criticism

722 Weitzman, M. L. 1992. On diversity. The Quaterly Journal of Economics 107: 363-405.

723 Wilson, E.O., Peters, F.M. (editors). 1988. Biodiversity. National Academy Press, 724 Washington.

725 Wittgenstein, L. 2001. Philosophical Investigations. Third Edition. Blackwell Publishing, $726 \quad$ Oxford.

\begin{tabular}{|l|l|}
\hline Property & Formal definition \\
\hline Reflexivity & For all $\mathrm{a}, \mathrm{X}^{\mathrm{a}} \geq \mathrm{X}^{\mathrm{a}}$ \\
\hline Transitivity & For all $\mathrm{a}, \mathrm{b}, \mathrm{c}, \mathrm{if} \mathrm{X}^{\mathrm{a}} \geq \mathrm{X}^{\mathrm{b}}$ and $\mathrm{X}^{\mathrm{b}} \geq \mathrm{X}^{\mathrm{c}}$ then $\mathrm{X}^{\mathrm{a}} \geq \mathrm{X}^{\mathrm{c}}$ \\
\hline Indifference & For all $\mathrm{i}, \mathrm{j},\{\mathrm{i}\} \sim\{\mathrm{j}\}$ \\
\hline Monotony & $\begin{array}{l}\text { For all } \mathrm{i}, \mathrm{j}, \text { if } \mathrm{i} \text { and } \mathrm{j} \text { belong to the same species then }\{\mathrm{i}\} \sim(\mathrm{i}, \mathrm{j}), \\
\text { otherwise }\{\mathrm{i}\}<(\mathrm{i}, \mathrm{j})\end{array}$ \\
\hline Independence & $\begin{array}{l}\text { If neither } \mathrm{X}^{\mathrm{a}} \text { nor } \mathrm{X}^{\mathrm{b}} \text { contain } \mathrm{i} \text {, then } \mathrm{X}^{\mathrm{a}}>\mathrm{X}^{\mathrm{b}} \text { if and only if } \\
\mathrm{X}^{\mathrm{a}} \mathrm{U}\{\mathrm{i}\}>\mathrm{X}^{\mathrm{b}} \mathrm{U}\{\mathrm{i}\}\end{array}$ \\
\hline
\end{tabular}
Table 1

$730 \quad \mathrm{i}, \mathrm{j}$ are individuals. $\mathrm{X}^{\mathrm{a}}, \mathrm{X}^{\mathrm{b}}, \mathrm{X}^{\mathrm{c}}$ are samples to be compared. " $>$ " stands for "is strictly more

731 diverse than", " $\sim$ " for "is just as diverse as", and " $\geq$ " for "is at least as diverse as". 


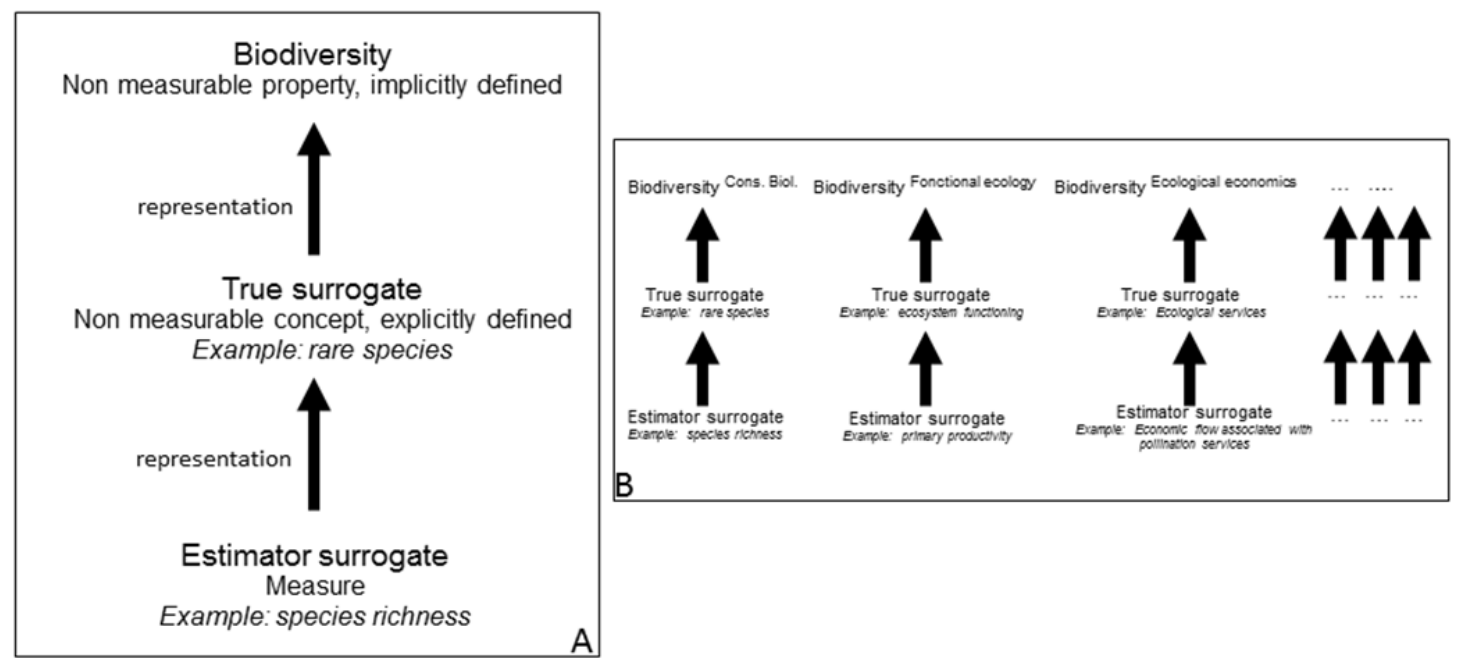

734

735 Figure 1. A. Surrogacy relations according to the conventionalist approach. B. Generalization

736 to other biodiversity sciences (this involves calling "surrogates" some concepts usually not

737 considered to be surrogates of biodiversity, e.g. ecosystem services). 


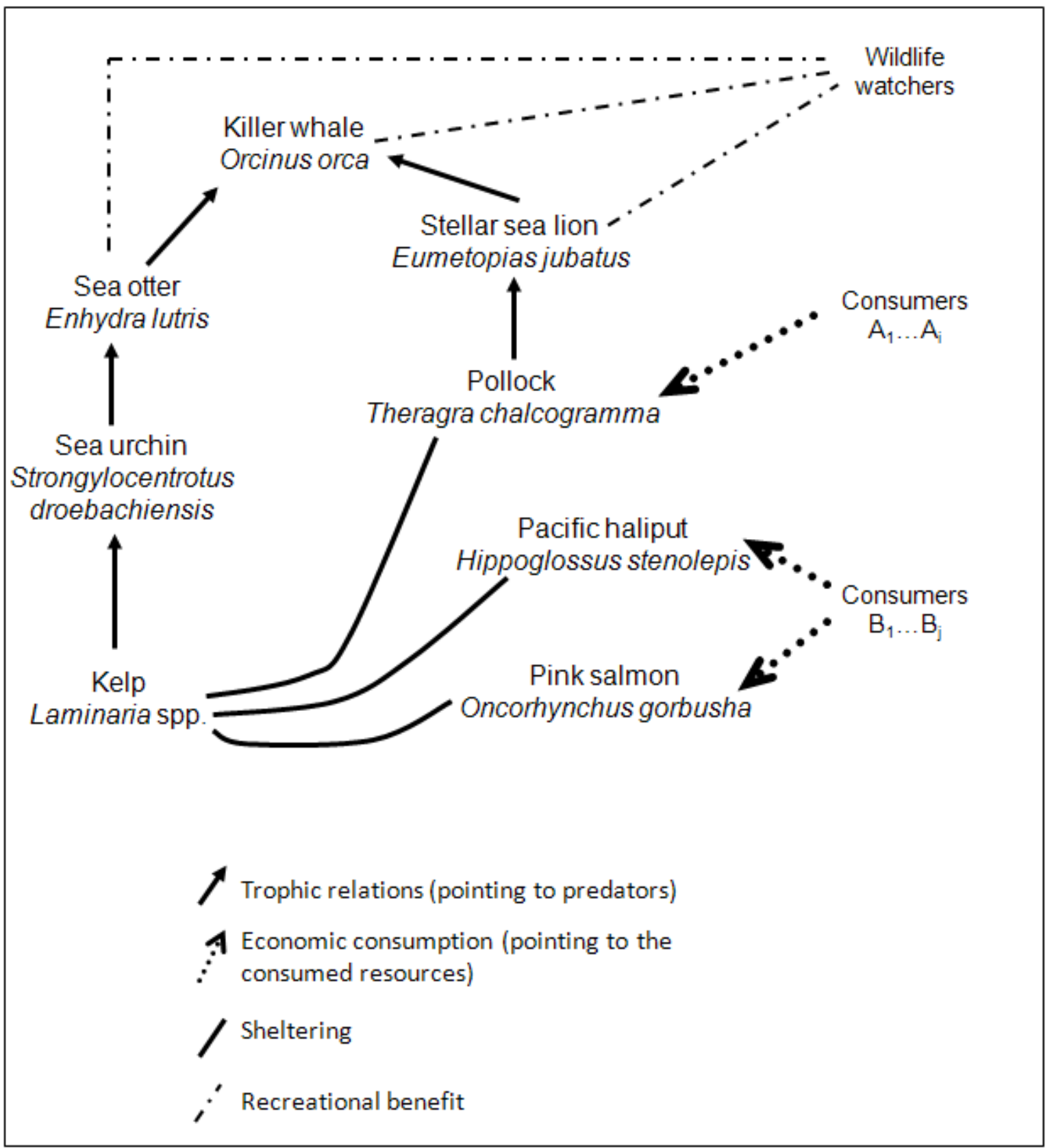

739 Figure 2. Consumers $A_{1} \ldots A_{i}$ consume pollocks. Overexploitation of pollocks leads to a

740 decrease of their predators stellar sea lions. As a consequence, killer whales consume sea-

741 otters, themselves consuming sea urchins, themselves grazing on kelp. Kelp being nurseries

742 for innumerable fish species consumed by human consumers $A_{1} \ldots A_{i}$ and $B_{1} \ldots B_{j}$, overfishing

743 pollock has an indirect impact on all these consumers. 